\section{P-240 CAN PRE-BEREAVEMENT SUPPORT FOLLOW MASLOW'S HIERARCHY OF NEEDS? A CASE STUDY}

Wendy Ashton. Eden Valley Hospice, Carlisle, UK

\subsection{6/bmjspcare-2019-HUKNC.262}

Background and aims Abraham Maslow (1943) proposed that motivation is a result of a person's attempt to fulfil five basic needs. This five-tier model suggests that needs lower in the hierarchy need to be met before you can move up the ladder. This motivation theory is person-centred and I have looked at how it can be transferred to working with children pre- and post- bereavement to achieve a positive outcome.

Pre-bereavement work with children and families takes on a similar trajectory beginning with basic needs/information about the illness and its effects, leading to self-actualisation/ realisation of death and dying with memories and treasures to keep in place. The aim is to support children step-by-step through bereavement. In my case study the aim was to create treasures to keep, make memories and understand about death and dying.

Case study/methods (see table 1 below).

\begin{tabular}{|c|c|}
\hline Maslow's needs & Pre-bereavement needs \\
\hline Physiological need & $\begin{array}{l}\text { Family reads books and chat with child. Including child in the } \\
\text { journey. }\end{array}$ \\
\hline Safety needs & $\begin{array}{l}\text { Introduction of Project Linus blankets. Child feels safe, secure and } \\
\text { comforted. }\end{array}$ \\
\hline $\begin{array}{l}\text { Belonging and } \\
\text { love needs }\end{array}$ & $\begin{array}{l}\text { Love and Laughter making lipstick kisses to keep. Feeling of } \\
\text { belonging to the family unit. }\end{array}$ \\
\hline Esteem needs & $\begin{array}{l}\text { Prior to last visit to say goodbye to mum; discussed with child about } \\
\text { giving mum a note and fabric heart to hold. Following visit, feeling of } \\
\text { accomplishment as she achieved what she set out to do. }\end{array}$ \\
\hline Self-actualisation & $\begin{array}{l}\text { Child wrote a message on a helium balloon and released into the sky } \\
\text { to remember mum whilst the funeral was on. Recognition that mum } \\
\text { no longer here. Creative activity and acceptance as mum popped out } \\
\text { from behind the cloud to say thank you. }\end{array}$ \\
\hline
\end{tabular}

Conclusion Using Maslow's Hierarchy of Needs theory enables a step-by-step pre-bereavement method that supports both the child and the family.

\section{P-241 GEMS - A GROUP-BASED APPROACH TO SUPPORTING CHILDREN AND YOUNG PEOPLE THROUGH BEREAVEMENT}

Jolanta Martis, Russ Hargreaves. ellenor, Kent, UK

\subsection{6/bmjspcare-2019-HUKNC.263}

Background The provision of hospice-based support and services to children and young people should be integral to the delivery of holistic care in an adult setting. Opportunities for remembrance, social connection and communication with others are important areas of bereavement support. Evaluation of service provision, feedback from users and staff identified the need for dedicated support available to children.
Coordinated and delivered by counsellors, music and play therapists, our GEMS (Grief Every Memory Special) group was established in 2016.

Aims To comprehensively evaluate our GEMS group programme, establishing a better understanding of a) those using the service and how to make it more accessible, b) children's feelings regarding support that is more therapeutically focused and/or fun-based, c) the role of peer support.

Methods Since 2016, 10 GEMS events have been held in a range of settings. This paper focusses on service evaluation, feedback analysis, internal and external consultation with both children and their guardians. We routinely gauged the number of referrals, visits and recurrence of attendance, feedback of children and families, conducted cost analysis and sought additional financial support to evolve the scope of provision available.

Results Of the 42 children supported: $67 \%$ had suffered bereavement of a parent, $21 \%$ a sibling and $12 \%$ a grandparent. Responses to each GEMS' event suggested children felt supported and engaged, valuing both fun/leisure activities and those with a therapeutic focus. Written and verbal feedback indicated children frequently engaged better in mixed-age groups and suggested GEMS' days worked best when following a theme.

Conclusion Evaluation of GEMS demonstrates children of all ages benefit greatly from the provision of activity-based bereavement support from teams of creative therapists and counsellors. This is a relatively inexpensive means of engaging a 'hard-to-reach' group, which all hospices should be encouraged to develop. Further focused research will enhance the GEMS programme.

\section{P-242 GRANDMA ON THE MOON - SUPPORTING CHILDREN WITH BEREAVEMENT}

Janet Hawksworth, Helen Brown. Kirkwood Hospice, Huddersfield, UK

10.1136/bmjspcare-2019-HUKNC.264

In partnership with Huddersfield Grammar School and AZtoB theatre company, a performance of 'Grandma on the Moon' was held in May 2019.

'Grandma On the Moon' is a performance exploring a child's understanding of loss and bereavement. Timmy aged 10, understands death means 'you don't come back', however, Poppy, age 5 doesn't. She wants to find her grandma to 'tell her something really important'. Using the imaginative play of children, they go on adventures through lands magical and familiar to try and 'find grandma'.

'Grandma in the Moon' aims to support young people and families through the bereavement process, encouraging us to have open, honest conversations around death. It shows how children grieve differently to adults and raises awareness of different support strategies to help manage conflicting emotions.

The play was performed twice, to two groups of children, with time in between for discussion. 160 children in total took part and feedback and reaction was wide ranging, with tears and laughter: 'I liked that they told everyone that it's ok to cry, get angry, or talk about when you lose someone'. 